\title{
Acción local de vacunas elaboradas con veneno de Bothrops alternatus en equinos productores de suero antiofídico
}

\author{
Bogado, F. ; Núñez, S. ${ }^{2}$; Mussart, N.B. ${ }^{3}$; Picot, J.A. ${ }^{4}$; García Denegri, M.E. ${ }^{5}$ \\ Cátedras de Clínica de Grandes Animales ${ }^{1}$ Inmunología ${ }^{2}$, Fisiología ${ }^{3}$, Bioestadística ${ }^{4}$, Zoología y Ecología \\ Facultad de Ciencias Veterinarias, Universidad Nacional del Nordeste (UNNE), Cabral 2139, Corrientes (3400), \\ Argentina, E-mail: efbogadol@yahoo.com.ar
}

\begin{abstract}
Resumen
Bogado, F.; Núñez, S.; Mussart, N.B.; Picot, J.A.; García Denegri, M.E.: Acción local de vacunas elaboradas con veneno de Bothrops alternatus en equinos productores de suero antiofídico. Rev. vet. 25: 2, 114-119, 2014. El objetivo del trabajo consistió en estudiar los efectos locales causados por sucesivas inoculaciones de veneno de Bothrops alternatus, en un grupo de tres equinos inmunizados para la producción de suero antiofídico monovalente. El adyuvante de Freund causó una respuesta importante para el estímulo inmunológico, en tanto que la inmunización con el veneno entero indujo sangrado local, edema, dolor y escape de enzimas del tejido muscular. La reacción local varió con las sucesivas vacunas, siendo constantes la hemorragia local y la inflamación, con formación de abscesos en las últimas inoculaciones. La actividad AST reveló elevaciones significativas de su tasa sérica, en tanto que LDH se incrementó de manera altamente significativa a partir de las $3 \mathrm{~h}$ con acmé a las 6 $\mathrm{h}$ y posterior descenso a las $24 \mathrm{~h}$. En la primera vacunación, CPK se elevó significativamente a las $3 \mathrm{~h}$ y registró un segundo pico a las $24 \mathrm{~h}$. Se observó una reducción de la magnitud de elevación de las actividades enzimáticas en las últimas inoculaciones (con altas dosis de veneno), quizás debido a que los anticuerpos preformados hayan conferido protección y reducido la destrucción de fibras musculares. Se concluye que los intensos efectos locales (dolor, hemorragia y posterior fibrosis local) imponen ensayar nuevas técnicas de inmunización a fin de minimizar los efectos adversos causados a los equinos.
\end{abstract}

Palabras clave: caballo, inmunización, Bothrops alternatus, enzimas musculares.

\begin{abstract}
Bogado, F.; Núñez, S.; Mussart, N.B.; Picot, J.A.; Garcia Denegri, M.E.: Local action of vaccines elaborated with Bothrops alternatus venom in anti-venom donor horses. Rev. vet. 25: 2, 114-119, 2014. The aim of this work was to study the local effects caused by successive vaccines prepared with Bothrops alternatus venom, in a group of three horses immunized for the production of monovalent antivenom. Freund's adjuvant caused a significant stimulus to the immune response, whereas immunization with the whole venom induced leakage of enzymes in muscle tissue together with local bleeding, edema and pain. Local reaction varied with successive inoculations, with bleeding and inflammation being a constant in all the cases, with formation of abscesses in the latter administrations. AST serum activity showed significant elevations, as long as LDH was increased in a highly significant way starting from the $3 \mathrm{~h}$ with a peak at $6 \mathrm{~h}$ and later descent at $24 \mathrm{~h}$. The first vaccination induced significant $\mathrm{CPK}$ elevations at $3 \mathrm{~h}$ and a second at $24 \mathrm{~h}$. Reduction of enzymatic activities were registered with the highest doses of venom, indicating that antibodies somehow prevented destruction of muscle fibers but not vascular damage, evidenced by bleeding observed in the latter inoculations. It is concluded that the intense local effects were caused by immunization (pain, hemorrhage and posterior fibrosis), suggesting the need of development of new immunization methods in order to minimize adverse effects in anti-venom donor horses.
\end{abstract}

Key words: horse, immunization, Bothrops alternatus, muscular enzymes. 


\section{INTRODUCCIÓN}

En el nordeste argentino habitan serpientes venenosas pertenecientes a distintos géneros tales como Bothrops (yarará), Crotalus (cascabel) y Micrurus (coral), las que ante un posible agresor se defienden mordiendo a la víctima y causándole una intoxicación. El mayor número de accidentes ofídicos es provocado por Bothrops alternatus (yarará grande ó víbora de la cruz) y Bothrops diporus (yarará chica) ${ }^{8}$.

En particular, el veneno de especies botrópicas de América Latina induce en la víctima una serie de efectos locales complejos que incluyen sangrado, mionecrosis y edema, en adición a efectos sistémicos como hemorragia, alteraciones en la coagulación de la sangre, shock cardiovascular y fallo renal agudo ${ }^{1,2,26}$, intoxicación que es tratada con la administración de sueros antiofídicos. En B. alternatus tales efectos son provocados por una variedad de componentes proteicos del veneno ${ }^{17}$, entre ellos fosfolipasa $A_{2}$, baltergina ${ }^{12}$ (metaloproteinasa), enzimas similares a trombina (trombinlike), L-aminoxidasas y desintegrinas, entre otras $19,23,24$.

La fisiopatología de la intoxicación ofídica es bien conocida, en tanto que han sido poco estudiados los efectos que causan dosis subletales de veneno administradas en animales para inducir la producción de inmunoglobulinas (anticuerpos), utilizadas en el tratamiento de la intoxicación ofídica. La única alternativa terapéutica para la intoxicación por accidente ofídico continúa siendo la administración de sueros hiperinmunes producidos en distintas especies animales tales como caballos 5, 13, 18, 21 y ovinos 3, 4, 6, 14, 15, 22 entre otras especies. Para ello se inmunizan los animales con dosis subletales progresivas de veneno entero, de manera que sus toxinas no causen la muerte, pero sí estimulen el sistema inmune produciendo anticuerpos.

Debido a que los venenos no generan memoria inmunológica, es necesario administrar más de una vacuna como así también reiniciar las vacunaciones en cada ciclo de producción de suero hiperinmune. Estos sueros antiofídicos están constituidos por una gran variedad de inmunoglobulinas que neutralizan los distintos componentes del veneno. Pueden ser monovalentes cuando en la inmunización de mamíferos se utilizan vacunas elaboradas con el veneno de una especie determinada de serpiente, en caso contrario polivalentes, cuando se utilizan vacunas elaboradas con mezclas de venenos de serpientes del mismo género y diferente especie o géneros diferentes, a fin de generar un amplio espectro de protección de la intoxicación respecto al veneno correspondiente a la especie de serpiente que causa el accidente ${ }^{9}$.

Los objetivos del trabajo consistieron en analizar los efectos locales agudos que provoca la inmunización con sucesivas vacunas elaboradas con dosis crecientes de veneno de yarará grande (B. alternatus) administradas a equinos para la producción de suero antiofídico monovalente. Asimismo, se planificó evaluar la respuesta a los adyuvantes utilizados durante la elabo- ración de los inóculos, que consisten en una emulsión de agua en aceite mineral conteniendo micobacterias muertas, en el caso del adyuvante completo de Freund (ACF) ${ }^{10}$.

\section{MATERIAL Y MÉTODOS}

Animales. Se utilizaron 5 equinos adultos de 3 a 4 años de edad, de 450 a $550 \mathrm{~kg}$, de los cuales dos de ellos operaron como controles. Previo a la inmunización, los animales fueron sometidos a exámenes clínicos y de laboratorio; desparasitados con febendazol $(7 \mathrm{mg} / \mathrm{kg})$ e ivermectina $(0,2 \mathrm{mg} / \mathrm{kg})$ y se les efectuó el test de Coggins (Lab. Inmunology) para descartar la presencia de anemia infecciosa equina. Sistemáticamente, luego de cada vacuna los animales fueron objeto de exámenes clínicos y extracciones de sangre para distintos estudios. Todos los experimentos fueron realizados bajo los estándares éticos y de bioseguridad para animales de experimentación según el Comité de Ética de la Facultad de Ciencias Veterinarias-UNNE (Protocolo $N^{\circ} 003$ ).

Preparación de la vacuna. El veneno de B. alternatus fue obtenido de ejemplares adultos del serpentario del Zoológico de la Ciudad de Corrientes, Argentina. Luego de la extracción, el veneno fue centrifugado y desecado, conservándose a $-20^{\circ} \mathrm{C}$ hasta el momento de su uso. Para la preparación del inóculo, el veneno fue disuelto en buffer fosfato (PBS, $\mathrm{pH} 7,2$ ) y filtrado a través de una membrana de nitrocelulosa de $0,22 \mu \mathrm{m}$ (Millipore). Finalmente fue mezclado con ACF en la primera aplicación y con adyuvante incompleto de Freund (AIF) en las restantes (Sigma-Aldrich, USA) inyectados en la tabla del cuello. Cada uno de los animales controles $(\mathrm{n}=2)$ recibieron $2 \mathrm{ml}$ de PBS y luego de una semana se administró AIF a uno de ellos y ACF al restante. El proceso de preparación de los inóculos fue realizado en condiciones de esterilidad.

Protocolo de inmunización. Los animales tratados recibieron un volumen final de $10 \mathrm{ml}$ (vía SC), aplicados en alícuotas de $2 \mathrm{ml}$ distribuidos en 5 puntos diferentes de la tabla del cuello, acorde al siguiente detalle: dosis inicial de $0,75 \mathrm{mg}$ más ACF, luego se continuó con dosis sucesivas crecientes a intervalos de 21 días a razón de 1,$5 ; 2,5 ; 5,5 ; 10 ; 15 ; 22 ; 30$ y $45 \mathrm{mg}$ de veneno, en estos casos con AIF.

Seguimiento clínico: la respuesta local fue controlada diariamente, tomando en consideración el estado general, cambios en la temperatura local, dimensiones de la reacción inflamatoria y modificaciones en la sensibilidad atribuibles a las vacunaciones. Periódicamente los caballos fueron analizados por técnicas de coprología cuantitativas.

Enzimograma muscular. Se tomaron muestras de sangre sin anticoagulante $24 \mathrm{~h}$ después de la inyección de las vacunas, realizadas a intervalos de 3,6 y $12 \mathrm{~h}$ 
para la obtención de suero. La determinación espectrofotométrica de creatinfosfoquinasa (CK) se efectuó por el método cinético UV (reactivos Randox Lab) basado en la medida de creatina formada en la reacción $\mathrm{ADP} /$ fosfocreatina, lecturas a $340 \mathrm{~nm}$. Para cuantificar la actividad de aspartato amino transferasa (AST) se utilizó el método UV optimizado c/ NADPH-oxoglutarato, lecturas a $334 \mathrm{~nm}$ (reactivos Wiener Lab). Para la determinación de lactato deshidrogenasa (LDH) se empleó el método UV optimizado con NADPH piruvato, lecturas a $340 \mathrm{~nm}$ (reactivos Wiener Lab).
Tabla 1. Respuesta de los animales controles $(\mathrm{n}=2)$ inoculados con los vehículos utilizados para las vacunas y de los animales vacunados $(n=3)$.

\begin{tabular}{|c|c|c|c|c|}
\hline \multirow[b]{2}{*}{ respuesta } & \multicolumn{3}{|c|}{ controles } & \multirow{2}{*}{$\begin{array}{c}\text { tratados } \\
\text { vacuna }(\text { veneno })+ \\
\text { PBS+ACF+AIF }(\mathrm{n}=3)\end{array}$} \\
\hline & $\begin{array}{c}\text { día } 0 \\
\text { PBS }(n=2)\end{array}$ & $\begin{array}{c}\text { día } 7 \\
\operatorname{AIF}(n=1)\end{array}$ & $\begin{array}{c}\text { día } 14 \\
\mathrm{ACF}(\mathrm{n}=1)\end{array}$ & \\
\hline inflamación & - & $12 \mathrm{~h}$ & $2 \mathrm{~h}$ & $8-10 \min$ \\
\hline temperat. local & - & + & ++ & +++ \\
\hline deformación & - & ++ & +++ & ++++ \\
\hline sensibilidad & - & + & ++ & ++++ \\
\hline anorexia & no & no & no & si \\
\hline decaimiento & no & no & no & si \\
\hline
\end{tabular}

PBS: buffer fosfato; AIF: adyuvante incompleto de Freund; CF: adyuvante completo de Freund.
Tratamiento local. El tratamiento de las lesiones causadas por las vacunas, consistieron en lavajes locales con solución de iodo-povidona y aplicación de una pasta cicatrizante conteniendo principios bacteriostáticos, fungistáticos, antisépticos y antimiásicos. En la etapa final de la inmunización, en algunos casos fue necesario utilizar un compuesto a base de enzimas proteolíticas (tripsina, alfa-quimotripsina, hialorunidasa) y dimetilsulfóxido-DMSO (Desbridan $\mathrm{T}^{\circledR}$ ), en aplicaciones intralesionales de aproximadamente $5 \mathrm{ml}$ en cada sitio, con el fin de disminuir las extensas áreas de fibrosis provocadas por el tejido cicatrizal.

Análisis bacteriológico del tejido con reacción inflamatoria. Los materiales para el análisis bacteriológico fueron recolectados en condiciones de esterilidad utilizando una jeringa de $5 \mathrm{ml}$. Las muestras se sembraron en medios para aerobios, Agar Sangre (Britania B0414984) y Agar McConkey (Britania 0211405) para bacterias y Agar Saboraud para hongos y levaduras.

Estadística. Los cálculos estadísticos fueron enmarcados en un diseño completamente aleatorizado, con arreglo factorial 4 por 7 (4 tiempos de control post-inoculación y 7 dosis diferentes de veneno). Con la finalidad de realizar un análisis preliminar de los resultados, se efectuó estadística descriptiva. Todas las variables en estudio cumplieron con los supuestos de normalidad, homogeneidad de las varianzas e independencia. Al realizar el análisis de la varianza (ANOVA), se observó interacción entre la dosis aplicada y el tiempo post-inoculación, indicando que los factores estudiados no actúan independientemente, por lo cual se realizó el análisis de los efectos simples del tiempo trascurrido desde la aplicación del veneno en las distintas dosis inoculadas. Para aquellas variables en las que se detectaron diferencias, las medias se compararon mediante la prueba de Tukey.

\section{RESULTADOS}

En todos los casos el test de Coggins acusó resultados negativos. Durante toda la experiencia los caba- llos se mantuvieron con coprología cuantitativa menor de $100 \mathrm{hpg}$. Del análisis bacteriológico de la piel de los distintos puntos de vacunación, tanto en caballos controles como en los inoculados con veneno, no se obtuvo aislamiento positivo en ninguna de las muestras para microorganismos aerobios.

En los animales controles se presentó reacción inflamatoria de intensidad variable, según fueran inoculados con PBS, ACF o AIF, resultados que se detallan en Tabla 1.

La Tabla 1 señala que las inoculaciones con PBS no produjeron cambios locales en ninguno de los dos equinos, solamente ausencia de apetito y decaimiento. En el equino inyectado con AIF, la inflamación local fue evidente a partir de las $12 \mathrm{~h}$, con incremento paulatino de la dimensión del área, que alcanzó 12 x 7,7 cm a las $24 \mathrm{~h}$, cediendo totalmente la tumoración a las $48 \mathrm{~h}$. Se acompañó de ligero incremento de la temperatura local y escaso aumento de la sensibilidad.

El caballo que recibió ACF manifestó una deformación en el área de inoculación a partir de las $2 \mathrm{~h}$, acompañado de aumento de la temperatura local. Inicialmente el edema fue de $5 \times 7 \mathrm{~cm}$, pero luego se intensificó alcanzando $24 \times 14 \mathrm{~cm}$ a las $24 \mathrm{~h}$. La deformación persistió y el tejido celular subcutáneo manifestó abundante tejido fibroso a la palpación, que permaneció luego de 45 días.

La exploración clínica del área de inoculación de las vacunas conteniendo veneno demostró que independientemente de las dosis aplicadas, la reacción inflamatoria local fue siempre intensa, caracterizada por edema inflamatorio con intenso dolor y calor, en principio, relacionado a los puntos de inoculación. Sin embargo, luego de transcurridas las primeras horas, tal edema inflamatorio se extendió a las regiones ventrales del cuello e incluso a los miembros, hecho atribuible a los efectos de la gravedad. Luego de $48 \mathrm{~h}$ se presentaron abscesos. Todos los animales respondieron satisfactoriamente al tratamiento local con la pasta cicatrizante.

El drenaje espontáneo de cada punto de vacuna se produjo a través de una fístula, mientras que en algunos casos fue necesario provocar dicho drenaje, la secreción fue de tipo sanguíneo-purulenta. Para minimizar 
las áreas de cicatrización se aplicó Debridan ${ }^{\mathrm{R}}$, cuya respuesta favorable ocurrió luego de 5 días. La resolución del proceso inflamatorio se produjo con fibrosis y sustitución por tejido conjuntivo, sin observarse grandes áreas de depresión por pérdida de tejido a consecuencia del efecto necrotizante del veneno.

Las tasas séricas de las enzimas obtenidas en los cinco animales (experimentales y controles) previamente a las vacunaciones fueron: AST: $65 \pm 5 \mathrm{mU} / \mathrm{ml}$, LDH: $85 \pm 5 \mathrm{mU} / \mathrm{ml}$ y CK: $65 \pm 6 \mathrm{mU} / \mathrm{ml}$. En los gráficos que muestran la evolución temporal de las enzimas, no fueron consideradas las dosis de 22 y $30 \mathrm{mg}$ de veneno por haber arrojado tasas séricas semejantes a las de $45 \mathrm{mg}$.

La Figura 1 indica que a las $3 \mathrm{~h}$ posteriores a la vacunación con distintas dosis de veneno, AST mostró variaciones significativas $p<0,05$, en las dosis de 1,50 y $15 \mathrm{mg}$ de veneno. Para enzima LDH no hubo diferen-

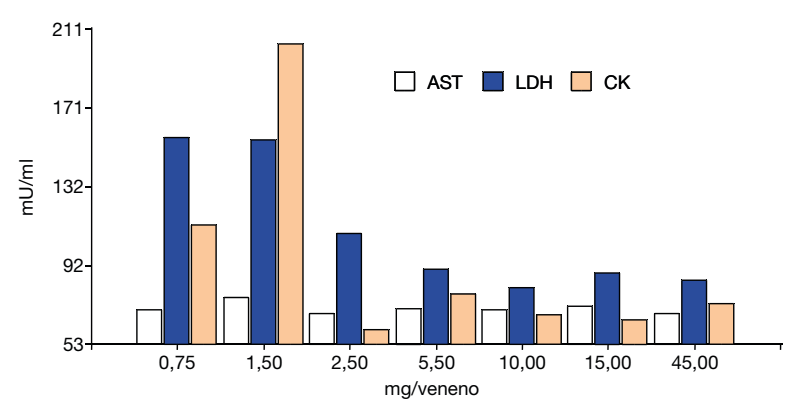

Figura 1. Tasa sérica de enzimas en equinos $(\mathrm{n}=3)$ vacunados con dosis progresivas de veneno de $B$. alternatus, $3 \mathrm{~h}$ posteriores.

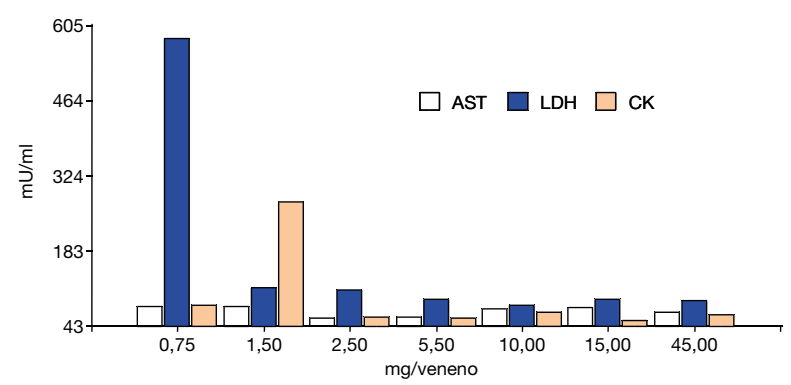

Figura 2. Tasa sérica de enzimas en equinos $(\mathrm{n}=3)$ vacunados con dosis progresivas de veneno de $B$. alternatus, $6 \mathrm{~h}$ posteriores.

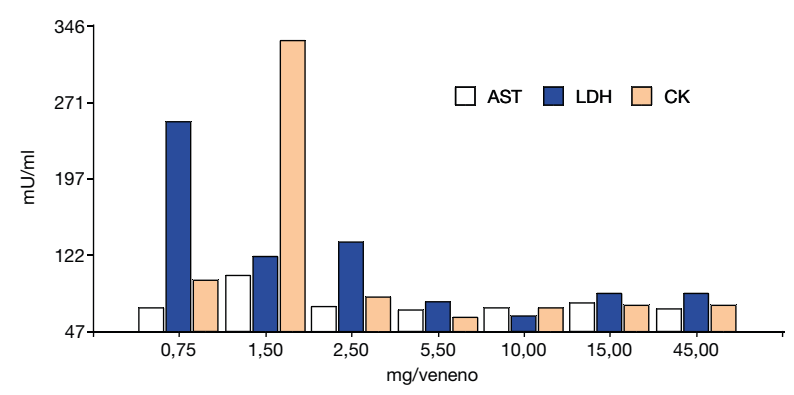

Figura 3. Tasa sérica de enzimas en equinos $(\mathrm{n}=3)$ vacunados con dosis progresivas de veneno de $B$. alternatus, $24 \mathrm{~h}$ posteriores. cias significativa para las dosis 15 y $45 \mathrm{mg}$, pero sí fueron estadísticamente diferentes, para las demás dosis partir de las $3 \mathrm{~h}$ posteriores a la vacunación. La actividad CK mostró igual comportamiento para las dosis de 10 y $15 \mathrm{mg}$ de veneno y diferencias significativas para las restantes dosis.

La Figura 2 muestra que a las $6 \mathrm{~h}$ posteriores a la vacunación, los valores de AST asumieron tasas similares a las dosis 2,50 y 5,50 mg de veneno. El mismo comportamiento se registró en las dosis de 0,75 y 1,50 $\mathrm{mg}$. Las demás dosis fueron diferentes entre sí. La respuesta de LDH fue similar para las dosis de 5,50; 15 y $45 \mathrm{mg}$, las que resultaron estadísticamente diferentes de las restantes. CK registró similar actividad a las dosis de 5,50 y $15 \mathrm{mg}$, de la misma manera que las dosis de 10 y $45 \mathrm{mg}$. En cambio, los valores registrados a las dosis de 0,75 y $1,50 \mathrm{mg}$ fueron significativamente distintos al resto y entre ellos.

La Figura 3 revela que a las $24 \mathrm{~h}$ de las vacunaciones, AST no reflejó variaciones entre las dosis de 0,$75 ; 2,50 ; 5,50 ; 10$ y $45 \mathrm{mg}$ de veneno, en tanto que las dosis de 1,50 y $15 \mathrm{mg}$ fueron diferentes entre ellas y las restantes. La respuesta de la enzima LDH fue estadísticamente significativa entre las dosis aplicadas, salvo las de $10 ; 15$ y $45 \mathrm{mg}$, las cuales registraron respuestas similares.

\section{DISCUSIÓN}

Desde el punto de vista clínico, en los equinos controles se observó que las administraciones de PBS y AIF causaron daños poco relevantes. En cambio, ACF provocó una deformación persistente y el tejido celular subcutáneo manifestó a la palpación abundante fibrosis que permaneció más de 45 días, posiblemente por participar activamente en el proceso inmunológico.

Los síntomas locales fueron más intensos en los caballos vacunados con veneno, quienes manifestaron las lesiones típicas del proceso inflamatorio agudo, con edema muy manifiesto, que se extendió hacia la zona pectoral acompañado de dolor y calor, evolucionando luego a la formación de abscesos acompañados de áreas necróticas que ulteriormente drenaron a través de una fístula. Una vez cureteado el absceso, el proceso de cicatrización fue rápido, aunque en algunas ocasiones fue necesario el uso de medicamentos para disminuir la formación de tejido cicatrizal.

Todas las vacunas causaron dolor en las primeras $24 \mathrm{~h}$, manifestado por las actitudes antiálgicas, anorexia, decaimiento y aumento de la sensibilidad a la palpación en el área de inoculación. Desde el punto de vista clínico, en los animales vacunados con veneno las manifestaciones fueron siempre las mismas.

En las distintas etapas de vacunación se utilizaron adyuvantes, sustancias que añadida a la formulación vacunal potencian la respuesta inmunitaria, circunstancia demostrada en este trabajo por la intensa reacción inflamatoria inducida, que se intensificó cuando fueron mezclados con los antígenos contenidos en el veneno. 
El ACF es uno de los adyuvantes más poderosos; su uso en medicina humana está vedado por ser muy reactogénico. En cambio, el AIF, la emulsión a la cual no se adicionó la micobacteria muerta, ha sido empleado en formulaciones vacunales en seres humanos ${ }^{25}$.

Los adyuvantes inmunológicos se comenzaron a desarrollar a partir de la segunda década del siglo XX, cuando Ramón y colaboradores observaron que los caballos que desarrollaban abscesos en el sitio de inyección del toxoide diftérico, generaban mayores títulos de anticuerpos específicos que aquellos que no los tenían. Posteriormente, se reportó que los abscesos generados por la inyección de sustancias extrañas junto con el toxoide, aumentaban la respuesta antitoxina en caba1 los ${ }^{19,20}$. En el presente trabajo se estima que los adyuvantes de Freund debieron estimular significativamente la respuesta de células dendríticas y macrófagos ${ }^{27}$.

Asimismo, los resultados aquí obtenidos confirman que los anticuerpos generados contra el veneno no neutralizan los efectos locales causados por el mismo, a pesar de que los tenores de dichos anticuerpos fueron suficientes para neutralizar los efectos sistémicos que provocaron las toxinas del veneno. Efectivamente, las dosis iniciales causaron lesiones coincidentes con las reportadas en accidentes naturales en el hombre ${ }^{16} \mathrm{y}$ en animales ${ }^{7}$, consistentes en hemorragia, mionecrosis y edema por acción de los componentes del veneno, posiblemente por activación de leucocitos y liberación de sustancias endógenas que generalmente evolucionan con pérdida parcial de tejidos y posterior cicatrización. Las vacunas posteriores con dosis incrementadas de veneno generaron lesiones que manifestaron activación del sistema inmunológico. Se observó organización del proceso inflamatorio con formación de abscesos de tamaños variables que luego fueron drenados.

Debe recordarse que el veneno causa aumento de permeabilidad vascular, estimula la infiltración polimorfonuclear con migración hacia el lugar de lesión, bajo la influencia de factores quimiotácticos y -ademásen los tejidos inflamados los macrófagos liberan enzimas lisosomales que aumentan la actividad fagocítica, así como proteasas que favorecen el efecto de limpieza del área lesionada ${ }^{27}$, clínicamente evidenciada por la formación de abscesos. Efectivamente, cada una de las vacunaciones con veneno, indujeron a la formación de granulomas y abscesos, cuya resolución fue más rápida a medida que se avanzaba en el protocolo de vacunación.

Las tasas séricas de las enzimas de localización muscular se incrementaron en concordancia con las lesiones descriptas ut supra. La actividad sérica de AST mostró moderados (aunque significativos) aumentos en todos los tiempos estudiados. A la dosis de $5,5 \mathrm{mg}$ de veneno, $\mathrm{LDH}$ se incrementó significativamente a partir de las $3 \mathrm{~h}$ con pico máximo a las $6 \mathrm{~h}$ y posterior descenso a las $24 \mathrm{~h}$. A la dosis de $2,5 \mathrm{mg}$ de veneno se registró una segunda elevación a las $24 \mathrm{~h}$. Otros investigadores registraron elevaciones enzimáticas en inoculaciones experimentales de dosis únicas de distintos venenos de serpientes del género Bothrops ${ }^{11}$.

En el presente ensayo, la primera vacunación produjo elevaciones de $\mathrm{CK}$ a las $3 \mathrm{~h}$, repitiéndose el patrón de segundo escape enzimático a las $24 \mathrm{~h}$, como ocurriera con LDH. Tales elevaciones indican daños causados por el veneno a las fibras musculares. Fue evidente que las primeras dosis de veneno causaron miólisis más intensas que las restantes. La subsiguiente reducción de actividad enzimática puede interpretarse como reflejo de un menor daño muscular, seguramente porque la mayor producción de anticuerpos protegió en cierta medida la destrucción de fibras musculares, no así el daño vascular evidenciado por la intensa hemorragia registrada incluso en la última vacuna. Similar evolución de las actividades AST, LDH y CK fueron detectadas durante la inmunización de equinos para la producción de suero antiofídico polivalente contra venenos de crotálidos ${ }^{5}$.

Los sueros antiofídicos polivalentes se obtienen utilizando mezclas de veneno con el objeto de ampliar el espectro de uso médico Los monovalentes son de mayor utilidad clínica por su eficacia en la neutralización de la intoxicación ofídica cuando se utilizan para el tratamiento de accidentes causados por la especie de serpiente cuyo veneno se utilizó en la producción del suero mencionado ${ }^{13}$. Independientemente de que las vacunas sean preparadas con uno solo o mezclas de veneno de varios géneros $\mathrm{y} / \mathrm{o}$ especies, los efectos locales son semejantes 9,13 . En este trabajo no se observaron riesgos para la salud o vida de los equinos inmunizados; no obstante se presentaron abscesos locales, fístulas y fibrosis en el sitio de inyección. Otras experiencias que utilizaron dosis única y elevada de veneno de Bothrops jararaca, Bothrops moojeni y Bothrops neuwiedii provocaron la muerte de los equinos ${ }^{11}$ con síntomas locales semejantes a los reportados en este trabajo.

El equino es una especie que responde satisfactoriamente al estímulo antigénico de veneno para la producción de suero antiofidico, aspecto ampliamente demostrado en la literatura consultada, la cual llamativamente, no hace mención a los intensos efectos locales que no dejan de ser relevantes por generar malestar en el animal con dolor en cada inoculación, pudiendo complicarse con laminitis, patología que no se presentó en el presente trabajo.

A manera de conclusión, se demuestra la magnitud de los efectos locales de la vacunación con veneno de $B$. alternatus (dolor, edema, hemorragia y posterior fibrosis local), los cuales imponen ensayar nuevas técnicas de inmunización a fin de minimizar los efectos adversos causados a los equinos. Futuras investigaciones deberían demostrar si algunas proteínas del veneno (de menor toxicidad pero alta antigenicidad) podrían ser utilizadas disminuyendo el número de inoculaciones en los equinos y logrando acortar el lapso de producción de anticuerpos, minimizando el sufrimiento de los animales utilizados en esta tarea. 
Agradecimientos: a la Lic. Laura Rey, Directora del Centro Productor de Suero Antiofídico de la Ciudad de Corrientes, por brindarnos el veneno utilizado.

\section{REFERENCIAS}

1. Acosta OC, Koscinczuk P, Sánchez Negrette M, Teibler P, Ruiz R. 1996. Efectos del veneno de Bothrops alternatus de Argentina sobre músculo y distintos órganos de ratones. Acta Phys Pharm et Ther Latin 46: 97-102.

2. Acosta OC, Koscinczuk P, Teibler P, Sánchez Negrette M, Ruiz R, Maruñak S, Bogarín G. 1998. Actividades hemorrágica y edematizante y alteraciones histológicas en almohadilla plantar de ratón inducidas por venenos de serpientes de los géneros Bothrops y Crotalus de Argentina. Toxicon 36: 1165-1172.

3. Al-Abdula I, Garnvwa J, Rawat S, Smith D, Landon J, Nasidi A. 2003. Formulation of a liquid ovine Fab-based antivenom for the treatment of envenomation by the Nigerian carpet viper (Echis ocellatus). Toxicon 42: 399.

4. Al-Asmari A, Al-Abdula I, Crouch R, Smith D, Sjostrom L. 1997. Assessment of an ovine antivenom raised against venom from the desert black cobra (Walterinnesia aegyptia). Toxicon 35: 141-145.

5. Angulo Y, Estrada R, Gutiérrez JM. 1997. Clinical and laboratory alterations in horses during immunization with snake venoms for the production of polyvalent (Crotalinae) antivenom. Toxicon 35: 81-90.

6. Ariaratnam C et al. 1999. A new monospecific ovine Fab fragment antivenom for treatment of envenoming by the Sri Lanka Russell's viper (Daboia Russelli Russelli): a prelimining dose-finding and pharmacokinetic study. $\mathrm{Am}$ J Trop Med Hyg 61: 259-265.

7. Báez A, Teibler P, Merlo W, Burna A, Badaró M, Solana M, Infileski R, Acosta O. 2005. Lesiones sistémicas en un canino por intoxicación ofídica. Rev Vet 16: 95-98.

8. Esteso SC. 2005. Ofidismo en la República Argentina, Ed. Arpón, Córdoba (Argentina), 176 p.

9. Estrada R, Chaves F, Robles A, Rojas E, Segura E, Gutiérrez JM. 1992. Hematologic values and serum enzymes in horses inoculated with snake venoms for the production of antivenins in Costa Rica. Rev Biol Trop 40: 95-99.

10. Freund J, Casals J, Hosmer EP. 1937. Sensitization and antibody formation after injection of tubercle bacili and parafin oil. Proc Soc Exp Biol Med 37: 509-513.

11. García M, Tokarnia CH, Farias M, Belo A, Oliveira CM, Freitas NF, Oliveira CH, Barbosa JD. 2011. Aspectos clínico-patológicos do envenenamento botrópico experimental em equinos. Pesq Vet Bras 31: 773-780.

12. Gay CC, Maruñak SL, Teibler P, Ruiz R, Acosta OC, Leiva LC. 2009. Systemic alterations induced by a $B o$ throps alternatus hemorrhagic metalloproteinase (Baltergin) in mice. Toxicon 53: 53-59.
13. Gutiérrez JM, Chávez F, Elizondo J, Avila C, Cerdas L. 1988. Production of monovalent anti-Bothrops asper antivenom: development of immune response in horses and neutralizing ability. Rev Biol Trop 36: 511-517.

14. Landom J, Smith D. 2003. Merits of sheep antisera for antivenom manufacture. $J$ Toxicol 22: 15-22.

15. León G, Valverde J, Rojas G, Lomonte B, Gutiérrez JM. 2000. Comparative study on the ability of $\operatorname{IgG}$ and Fab sheep antivenoms to neutralize local hemorrhage, edema and myonecrosis induced by Bothrops asper (terciopelo) snake venom. Toxicon 38: 233-244.

16. Nakasone AA, Ivancovich NV. 2002. Ofidismo. Revista de Posgrado de la VIa Cátedra de Medicina (UNNE). http://med.unne.edu.ar/revista/revista114/ofidismo .htm

17. Öhler M, Georgieva D, Seifert J, von Bergen M, Arni RK, Genov N, Betzel C. 2010. The venomics of Bothrops alternatus is a pool of acidic proteins with predominant hemorrhagic and coagulopathic activities. J Proteome Res 9: 2422-2437.

18. Pratanaphon R, Akesowan S, Khow O, Sriprapat S, Ratanabanangkoon K. 1997. Producction of highly potent horse antivenom against the Thai cobra (Najakaouthia). Vaccine 15: 1523-1528.

19. Ramon G. 1925. Sur l'augmentation anormale de l'antitoxine chez les chevaux producteurs de serum antidiphterique. Bull Soc Centr Med Vet 101: 227-234.

20. Ramon G. 1926. Procedes pour accroïtre la production des antitoxins. Ann Inst Pasteur 40: 1-10.

21. Sjostrom L, Abdulla I, Rawat S, Smith D, Landom J. 1994. A comparison of ovine and equine antivenoms. Toxicon 32: 427-433.

22. Smith D, Reddi K, Laing G, Theakston D, Landom L. 1992. An affinity purified ovine antivenom for the treatment of Viper aberus envenoming. Toxicon 30: 865-871.

23. Smolka MB, Marangoni S, Oliveira B, Novello JC. 1998. Purification and partial characterization of a thrombin-like enzyme, balterobin, from the venom of Bothrops alternatus. Toxicon 36: 1059-1063.

24. Stábeli RG et al. 2006. Bothrops moojeni myotoxin-II, a Lys49-phospholipase A2 homologue: An example of function versatility of snake venom proteins. Comp Biochem \& Phys, Part C 142: 371-381.

25. Stuart CH. 1969. Adjuvant influenza vaccines. Bull WHO 41: 617-621.

26. Teibler P, Acosta OC, Maruñak S, Ruíz R, Koscinczuk P, Sánchez Negrette M, Coppo NB. 1999. Lesiones locales y sistémicas inducidas por veneno de Bothrops alternatus (víbora de la cruz) de Argentina. Acta Tox Arg 7: 7-10.

27. Tizard IR. 2009. Introducción a la Inmunología Veterinaria, $8^{\circ}$ ed., Elsevier, Barcelona, 574 p. 